\title{
Norois
}

Environnement, aménagement, société

226 | 2013

Commerce et développement local, déplacements urbains, valorisations agricoles, découpages

électoraux

\section{Les espaces de masculinités}

\section{Raymonde Séchet}

\section{(2) OpenEdition \\ Journals}

Édition électronique

URL : http://journals.openedition.org/norois/4624

DOI : $10.4000 /$ norois. 4624

ISBN : 978-2-7535-2287-9

ISSN : $1760-8546$

\section{Éditeur}

Presses universitaires de Rennes

\section{Édition imprimée}

Date de publication : 30 mars 2013

Pagination : 110-112

ISBN : $978-2-7535-2285-5$

ISSN : 0029-182X

Référence électronique

Raymonde Séchet, «Les espaces de masculinités », Norois [En ligne], 226 | 2013, mis en ligne le 30 mars 2013, consulté le 23 septembre 2020. URL : http://journals.openedition.org/norois/4624 ; DOI : https://doi.org/10.4000/norois.4624 


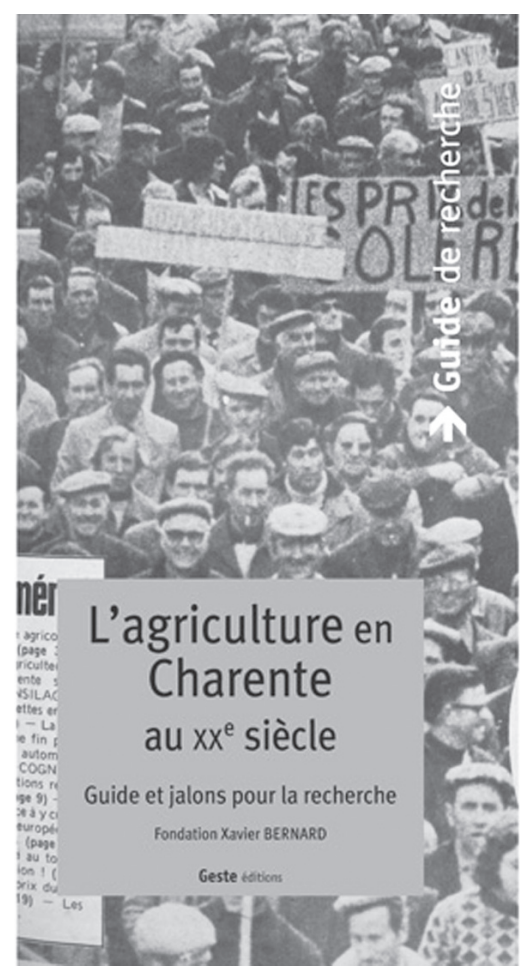

après une présentation des paysages et des principales spéculations agricoles du département, est rappelée à grands traits l'histoire de l'agriculture depuis les débuts du XIX ${ }^{e}$ siècle. Un long chapitre est consacré au cognac, notamment aux maisons de négoce et au conservatoire du vignoble charentais.

Puis est rappelé, dans ce département saigné par l'exode rural, l'importance des migrations depuis les départements de l'Ouest, et le rôle novateur joué par ces agriculteurs venus d'ailleurs. Les principales structures responsables du développement agricole au long du siècle sont successivement présentées : syndicalisme, administration, organismes de vulgarisation, de développement et de formation, presse, responsables agricoles, notamment les ministres charentais de l'agriculture ( Maurice Raynaud, Jean Hennessy, Félix Gaillard)

L'originalité de l'ouvrage est la présentation des sources archivistiques et de la bibliographie concernant le sujet qui occupe près de la moitié du texte.

Aussi la collection, si elle est menée à bien, devrait constituer, à terme, un remarquable outil à disposition des chercheurs en sciences sociales sur l'agriculture de la France.

On ne peut que souhaiter la mobilisation des chercheurs ruralistes sur les autres départements afin que cet ambitieux projet aboutisse. L'aide de la fondation Xavier Bernard assure financièrement la publication de ces ouvrages, ce n'est pas mince.

Jean RENARD

\section{Charlotte Prieur, Louis Dupont (dir.), 2012. Les espaces de masculinités, Revue Géographie et Cultures, $\mathrm{n}^{\circ} 83$, Paris, L'Harmattan.}

Les travaux sur les constructions de genre et les sexualités occupent une place certes croissante mais encore faible dans la géographie française. Cela est tout particulièrement vrai pour les masculinités. Ce numéro de la revue Géographie et cultures dirigé par Charlotte Prieur et Louis Dupont vient donc combler un vide. Il réunit 7 textes ainsi qu'un fort utile ensemble regroupant des recensions d'ouvrages et la présentation de deux films (Laurence Anyways et Skins) portant sur les sexualités et les corps dans les espaces. Le premier texte (Charlotte Prieur et Louis Dupont. État de l'art : géographies et masculinités) et le dernier (Karine Kaplan. Les géographies des sexualités et la géographie française peuvent-elles faire bon ménage? Une revue critique des géographies des sexualités anglophones) rendent compte de la richesse des apports heuristiques des travaux de géographes anglophones et de l'intensité des débats théoriques et idéologiques ayant animé ce champ d'étude des sexualités né au début des années 1980.

Les trois grands ensembles de questionnements ou d'orientations de recherche qui structurent ces travaux s'inscrivent respectivement dans les études gaies, les études féministes, les études queer. Si les deux premiers se rejoignent dans l'analyse des dynamiques spatiales comme produit d'un système à la fois capitaliste et patriarcal, tous convergent dans la déconstruction des catégories préétablies. Les sexualités sont dès lors pensées comme «sys- 


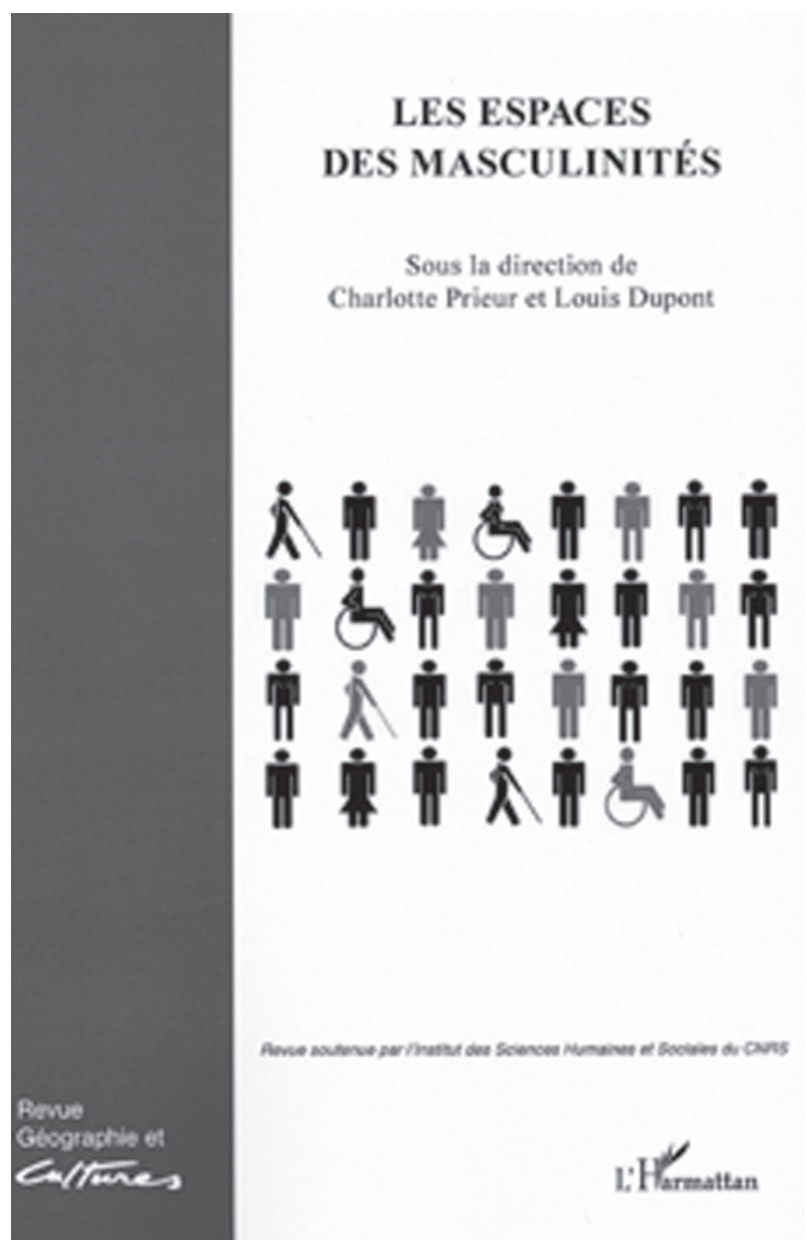

tème de conceptualisation entourant les pratiques sexuelles, et non seulement au sens de pratiques sexuelles » (Kaplan, p. 119). La question des lieux où se déroulent les actes n'en est pas moins importante. En effet, « la sexualité a fondamentalement une dimension spatiale, comme l'espace a une dimension sexuelle » (Stéphane Leroy. "Tu cherches quelque chose?" : ethnogéographie de la drague et des relations sexuelles antre hommes dans le Bois de Vincennes, p. 53), et le sexe est " créateur et « détourneur» de sens des lieux» (Nicolas Boivin. Territoires hédonistes $d u$ sexe : pour une géographie des subjectivations, p. 91). Pour le montrer, Nicolas Boivin a emprunté à Michel Foucault analyse le détournement des lieux par les pratiques sexuelles dans des espaces ne relevant pas de l'intimité, et cela en déconstruisant le "système de contrôle des plaisirs » inhérent aux «idéologies castratrices » (p. 94) propres chaque société, alors que Stéphane Leroy a porté son attention sur les reconfigurations des lieux par le développement d'un sociabilité spécifique aux « hommes entre eux » (p. 60).

Leurs interrogations sur le rôle de l'espace dans les constructions identitaires gaies ont amené des géographes à s'interroger sur le rôle joué par les gays dans les processus de gentrification. Face aux discriminations qui marginalisent, les villages gais font figure de refuges communautaires et de points d'appui pour des territorialisations dissidentes ou émancipatrices. Toutefois, dans le contexte de mondialisation du tourisme et des loisirs, la récupération par les acteurs de la promotion des espaces gais en tant qu'espaces créatifs, commerciaux, touristiques a contribué à faire émerger une homonormativité gaie (Kaplan, p. 122) qui s'avère, elle aussi, discriminante sur la base de frontières de classe, de race et de genre.

Dans le sillage de Doreen Massey, des géographes féministes ont cherché à montrer en quoi l'espace est une composante du système patriarcal qui assujettit les femmes. Le concept relationnel de genre a permis le décryptage de la spatialisation des rapports sociaux de sexe, du sexisme ambiant dans les espaces urbains et de "l'oppression spatiale et corporelle des femmes par les normes de genre dans les espaces urbains » (Kaplan, p. 125) et les lieux de travail. Les espaces de contrôle des pratiques sexuelles que sont les prisons (Gwénola Ricordeau, Olivier Milhaud. Prisons : espaces du sexe et sexualisation des espaces) n'échappent pas aux représentations dominantes de genre et de rôles sexuels en vigueur en dehors. Les pratiques sexuelles de compensation et de substitution qui s'y développent sont imprégnées par le primat de l'hétérosexualité (p. 71).

La déconstruction de la norme hétérosexuelle et de la naturalité du binôme homme/femme est au cœur du projet queer en géographie. Surface d'inscription des normes de sexe et de genre, le corps est aussi site de contestation et de résistance à l'hétéronormativité. Dans le sillage de Judith Butler ${ }^{1}$, l'accent a été mis sur les performances corporelles et la déconstruction des catégories de sexualité au risque, sous l'influence de l'ancrage postmoderne des chercheur-e-s, de se focaliser sur les aspects discursifs. Résolument inscrits dans la mouvance critique, articulant discours et matérialité, les travaux plus récents de la deuxième vague de la géogra-

1. Judith Butler, 1990, Gender trouble, New York/London, Routledge. 
phie queer explorent « la façon dont les différentes formes de hiérarchies viennent conjointement structurer les catégories supposément unitaires de sexualité, telles gay ou lesbienne » (Kaplan, p. 130). Particulièrement populaire dans le Village de Montréal, Mado, personnage de drag queen créé et performé par Luc Provost (Charlotte Prieur. Luc Provost présente Mado), pousse très loin cette déconstruction des catégories de genre: «Mado, ce n'est pas un homme, ce n'est pas une femme, c'est une chose intelligente» (Prieur, p. 112).

La déconstruction de la naturalité puis celle de la partition binaire entre hommes et femmes permise par les études de genre et les études queer ont permis de penser le masculin et le féminin au pluriel. La masculinité n'est pas un attribut lié au corps de l'homme mais une construction normative qui distingue la masculinité hégémonique - celle qui est à l'origine des systèmes de conformité entre sexe et genre, de l'inscription des normes dans les espaces - et marginalise d'autres formes de masculinités liées à la classe, la race, la sexualité ou encore aux apparences corporelles. Les autres formes de masculinité, y compris féminines, sont perçues comme plus ou moins subversives; des homosexualités sont tolérées pendant que d'autres sont réprimées parce que visibles (Leroy). Comme les rapports de sexe et les constructions de genre, cette masculinité hégémonique est situationnelle en ce sens où elle varie selon les cultures. En intervenant dans la fabrique des espaces, elle détermine des lieux d'appartenance et des représentations des formes d'entre-soi minoritaires par les populations majoritaires (Prieur, Dupont, p. 20).

La production du savoir est, elle aussi, située. Outre la dénonciation de la naturalité des identités, les travaux sur les masculinités et les féminités ont contribué aux questionnements sur la réflexivité du chercheur et les conditions de production du savoir scientifique (Prieur et Dupont, p. 25) en contestant les certitudes des chantres de l'objectivité qui croient pouvoir - si tant est qu'ils se posent la question - se départir de leur corps et de leurs émotions (Duplan, p. 125)², de leurs expériences et du système de valeur qui les imprègne.

2. D’après Rose Gillian, 1997, Situating knowledges: positionality, reflexivities and other tactics, Progress in Human Geography, vol. 21, n 3 , p. 305320 .

112
La critique ayant souvent été adressée à la géographie physique, Anne Jégou, Antoine Chabrol et Edouard de Bélizal (Rapports genrés au terrain en géographie physique) ont réalisé une enquête par questionnaire et entretien auprès des géographes physiciens français pour interroger la construction androcentrique de la géographie. Des enquêté-e-s se refusant à adopter le point de vue féministe ont pratiqué l'esquive devant des questions délicates, arguant de la nécessaire neutralité et niant les enjeux de genre alors que tout montre la persistance des enjeux de sexe, notamment sur le terrain. Ce terrain, légitimité scientifique du géographe physicien, il faut l'arpenter, s'y engager dans un corpsà-corps quand il est difficile d'accès, le dominer et le conquérir. Et si, masculiniste, la géographie physique n'est pas pour autant masculine, c'est que des figures féminines y ont inventé une masculinité féminine (p. 45) qui a contribué à son androcentrisme.

Au final, ce numéro de Géographie et Cultures qui arrive en pleine actualité politicienne française (débats en faveur du mariage pour tous bien sûr, mais aussi engagement de la Conférence des Présidents (!) d'université pour établir la parité dans les instances universitaires) est une contribution majeure au travail épistémologique qui s’impose en géographie comme ailleurs pour mettre à jour les dispositifs de hiérarchisation qui (re)produisent les rapports de domination et les marginalisations - dont les dispositifs spatiaux. L'espace n'est pas un simple contenant, il est produit social, support et enjeu des rapports sociaux, de tous les rapports sociaux, dont ceux de genre et de sexe, ni plus ni moins que les autres.

Raymonde SÉchet 